\title{
Evaluation of River Ecological Status in Plain River Network Area under the Background of Urbanization
}

\section{Li Ren ( $\nabla$ renli@hhu.edu.cn )}

Hohai University

Shuping Song

Hohai University

Yue Zhou

Hohai University

\section{Research Article}

Keywords: River ecological status, River ecological status evaluation, Index system, Urbanization, Plain river network, Jiangsu Province

Posted Date: October 18th, 2021

DOI: https://doi.org/10.21203/rs.3.rs-765547/v1

License: (9) This work is licensed under a Creative Commons Attribution 4.0 International License. Read Full License 


\title{
Evaluation of River Ecological Status in Plain River Network Area under the Background of Urbanization
}

\section{Li Ren ${ }^{1}$ (1) $\cdot$ Shuping Song ${ }^{1} \cdot$ Yue Zhou ${ }^{1}$}

Received: 20 July 2021 / Accepted:

(C) The Author(s), under exclusive licence to Springer Nature B.V. 2021

\begin{abstract}
21 main streams and tributaries of typical rivers in Jiangsu Province were taken as the research objects to evaluate river ecological status under the background of urbanization in this paper. A system of river ecological evaluation indexes and the evaluation model for plain river network area were constructed, including 4 indexes of aquatic environment, natural ecological system, social service function and water management and protection, and 12 pieces of divided criteria. The ecological status of these rivers in Jiangsu Province was evaluated, of which $71.4 \%$ were good. Analyzing the impact of urbanization on the ecological condition of rivers, we came to the conclusion that the level of river ecological status is decreasing with the improvement of urbanization level, and put forward that the reference value of the ISC red line of river ecological condition from good to medium in the urbanization plan of ecological river construction is $28 \%$.
\end{abstract}

Keywords River ecological status; River ecological status evaluation; Index system; Urbanization; Plain river network; Jiangsu Province

\footnotetext{
* Li Ren

renli@hhu.edu.cn

${ }^{1}$ College of Hydrology, faculty of Hydrology and Water Resources, Hohai University, Nanjing, Jiangsu, 210098
} 


\section{Introduction}

River is the source of life and the foundation of human activities. With the advancement of urbanization, river ecological status in plain river network area has been affected to varying degrees. Water pollution, insufficient ecological water and shrinking aquatic environment have also been apparently widespread, and river ecological problems are increasingly prominent.

A large number of studies have shown that urbanization affects land use and increases the impervious area, so urbanization is evidently correlated with surface runoff(Kim and Li et al., 2016), which changes the hydrological conditions of the basin and increases the flood risk(B and B et al., 2016). Meanwhile, human activities such as urbanization have intensified water pollution(Tatenda and Ross et al., 2020), and in plain river network areas, the impact of urbanization on river ecological conditions is also more significant. Human urbanization activities maximize the transformation of water resources into economic value, but also greatly undermine the integrity of river ecosystems and biodiversity(Vörösmarty and McIntyre et al., 2010) . Brabec, Meyer et al. (Elizabeth and Stacey et al., 2002; Paul and Meyer, 2008) found that when the surface impervious coefficient exceeds a certain threshold between $10 \%$ and $30 \%$, it will affect the hydrological conditions, water quality and biodiversity of the river. Spatial urbanization has changed regional hydrology and water quality in the Upper Ganga river basin in India. What's more, results revealed that the improvement of urbanization had a high impact on hydrological parameters: the water yield of the basin increased by $32.1 \%$, the annual average surface runoff increased by $84.6 \%$, and the evapotranspiration (ET) decreased by 14.7\% (Anoop and Chandra et al., 2020). Affected by the rapid development of urbanization, the difference of annual precipitation and flood season precipitation in cities and suburbs of the Yangtze River Delta has expanded, and the annual runoff and runoff coefficient have also increased. In the 
meantime, in the process of urbanization, the river network system has been greatly damaged, and the risk of flood and water quality degradation has markedly increased(Youpeng and Jintao et al., 2010). Therefore, the urbanization process has a great impact on the change of river ecological conditions.

With the improvement of people's environmental and ecological consciousness, the problem of river ecological condition has attracted more attention. As early as the 1980s, some scholars began to study the evaluation of river ecological conditions. The common methods of river ecological evaluation can mainly be divided into two kinds, including the biological index method and the comprehensive index method.

For the biological index method, there are many mature evaluation systems. In recent years, several countries have carried out more in-depth exploration and extension on the basis of existing theories. Meador(Meador and Whittier et al., 2008) carried out the IBI evaluation system in the western United States, standardized the regional IBI, evaluated the response of IBI to watershed land use, and evaluated its accuracy and consistency with watershed scale. However, in this method, the correlation between IBI index score and land use is not significant, and it is impossible to distinguish agricultural and urban dominant areas by IBI index score. Krisanti et al. (Krisanti and Wardiatno et al., 2017) used benthic macroinvertebrates to evaluate the ecological status of the source of the Cisadane River. The biological index was used as a numerical estimation of river health, which was of good applicability and not easily affected by regional differences. Nevertheless, the number of benthic macroinvertebrates was vulnerable to changes in environmental characteristics such as river width, depth, sediment type, flow velocity and physical or chemical variables, which could not reflect the actual ecological status of the river. Carlos et al. (Pinheiro and Oliveira et al., 2020) evaluated the 
ecological status of a Mediterranean river through the analysis of benthic diatoms and invertebrate communities, as well as physical, chemical and hydrological morphological parameters, which was more accurate than the single-index and single-population evaluation method. But the evaluation index would be greatly disturbed due to seasons, agricultural pollution and other changing reasons. To determine the actual situation of rivers, the further comprehensive evaluation is still needed.

The study of biological index method is mostly confined to the natural ecological context. Although it can reflect the health level of river ecosystem, its evaluation process rarely considers human influence and pays little attention to factors such as river' s social service function, which is insufficient to reflect the comprehensive ecological status of rivers. Therefore, it is essential to carry out the study of comprehensive index method for river ecological status evaluation.

Many scholars have evaluated the ecological status of rivers in different regions from various aspects by comprehensive index method. Based on the definition of river system health, Zhang et al. (Zezhong and Qingqing, 2016) constructed the health evaluation index system of Qilihe River system with 15 secondary indexes, and used the cloud evaluation model to evaluate the health of Qilihe River system, but the correlation of its characterization factors was not further verified. Zhu et al. (Zhu and Jia et al., 2019) established a health assessment framework system according to the characteristics of the main stream of the middle and lower reaches of the Hanjiang River, which consists of five criteria layers and 13 evaluation indexes from two aspects of ecological integrity and social service function. It is that when the index weight of AHP method fluctuates in a small range, the health status score of the study section changes little. However, in the evaluation process, there is a lack of continuous and systematic data, and the selection of partial individual indicators is insignificantly represented. Pan et al. (Pan and Xu et al., 2015) discussed the change rule of river health status under the background of 
urbanization based on entropy-weight and mater-element model, selected eight eco-hydrological indicators to establish an evaluation system, and concluded that the river health status was seriously deteriorated in the process of urbanization. Regardless, the identification sensitivity of individual indicators was still insufficient in their model, and the classification standard framework of each indicator still needed to be further improved.

At present, the evaluation system of river ecological status in plain river network areas is not complete and universal, and the evaluation method is defective. There are few studies on the evaluation of river ecological status considering the influence of urbanization. It is still essential to carry out multi-objective and multi-level analysis through more practice, and carry out the research on the evaluation system of river ecological status in line with the actual situation in China, so as to reflect the real situation of rivers objectively and provide data and theoretical basis for the construction of ecological rivers. Therefore, in this paper, we studied the evaluation of river ecological status under the background of urbanization, focusing on how to determine the index weight for constructing the evaluation model of river ecological status. Finally, the impact of urbanization on river ecological conditions is analyzed.

\section{Overview of the research area and research methods}

\subsection{Overview of the research area}

The study area, Jiangsu, is located in the eastern coast of China, belonging to the Yangtze River Basin and the Huaihe River Basin. The Yangtze River runs through Jiangsu Province from west to east with abundant water resources. There is a well-developed water network densely distributed among 
Jiangsu Province, which covered with natural ditches, artificial channels and more than 290 lakes large and small, including Taihu Lake and Hongze Lake, two of five largest freshwater lakes in China.

Jiangsu Province, one of the highest comprehensive developed provinces in China, is dominated by plains, with superior natural environment, high urbanization level, long history of agricultural civilization, and relatively early exploration of river ecological protection, which is typical and representative in the plain areas of the middle and lower reaches of the Yangtze River. Therefore, the researches on river ecological conditions in Jiangsu enjoy great reference significance for similar regions.

\subsection{Selection and classification of typical rivers}

According to the characteristics of the river basin in Jiangsu Province, a total of 21 provincial rivers (including basin rivers and cross-basin water transfer backbone rivers) were selected as typical rivers in this study from 3 watershed of the Huaihe River, Yangtze River and Taihu Lake. Among them, 15 rivers were selected in total from the Huaihe River Basin, including Huaihe River, Zhongyun River, Xinyi River, Yi River, Shu Rivera, Huai-Shu River, New Huaihong River, Old-yellow River, Liyun River, Taidong River, Tongyu River, Sanyang River, Tong River, Xuhong River and Bulao River. Three rivers were sorted out in the Yangtze River basin, specifically Chuhe River, Yangjiang River, Qinhuai River, and others in the Taihu Lake basin, including Wangyu River, Jiangnan Canalwere. The typical river system of Taipu River is shown in Fig. 2.1.

Based on the remote sensing satellite data in 2017, the impervious coefficient of the river basin, namely the ratio of impervious surface cover (ISC) to its watershed, was calculated to characterize the urbanization level of the river. Studies have shown that when the impervious coefficient is greater 
than a certain value (between $10 \%$ and $30 \%$ ), the ecological status of the river will be seriously damaged(Meyer, 2001; Elizabeth and Stacey et al., 2002). In order to analyze the impact of urbanization on the ecological status of rivers, we classify rivers with impervious coefficients less than $10 \%, 10 \%-30 \%$ and more than $30 \%$ into rivers with low urbanization, medium urbanization and high urbanization levels. The specific samples and classification in Jiangsu Province are shown in Table 2.1.

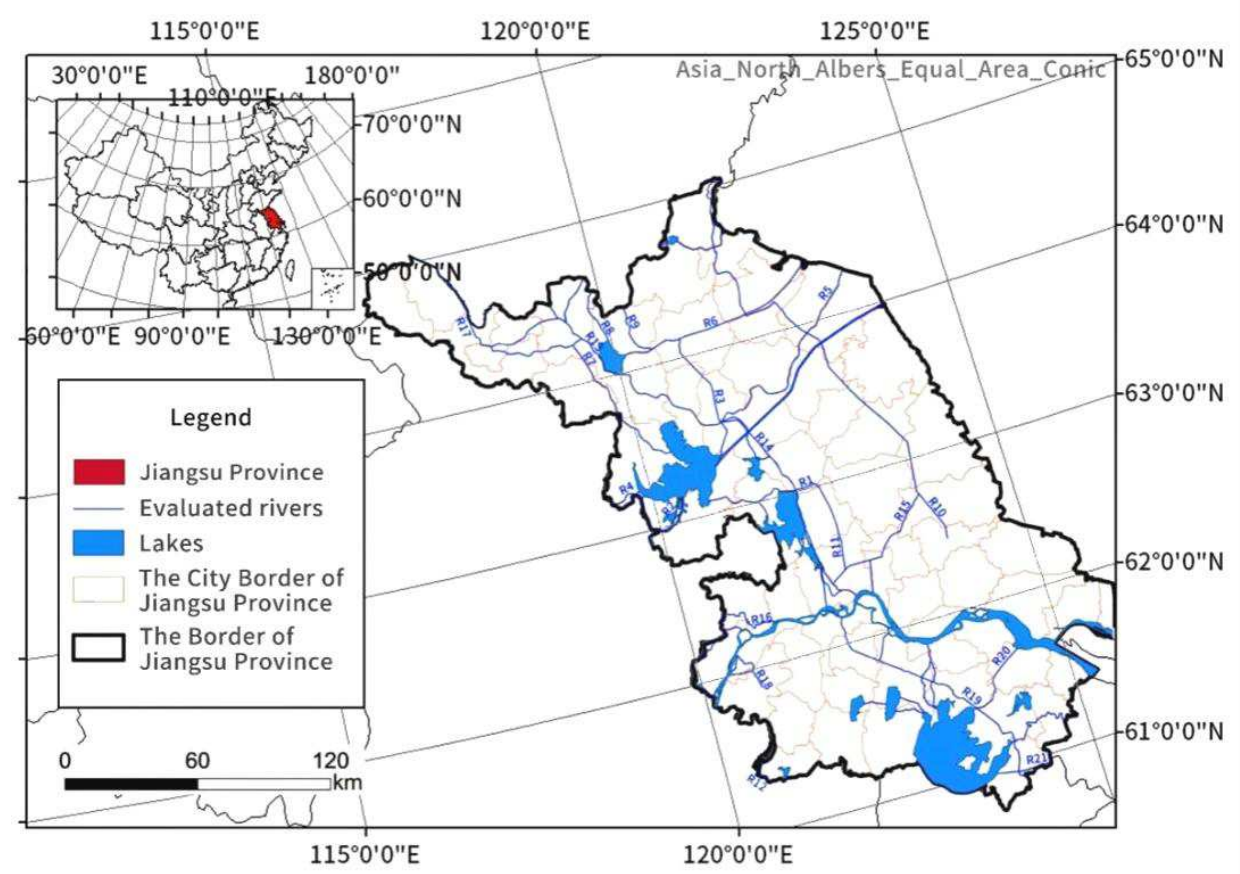

Fig. 2.1 The diagram of typical river

Table 2.1 Typical rivers and classification table

\begin{tabular}{|c|c|c|}
\hline Impervious coefficient & Urbanization level & River name and number \\
\hline Less than $10 \%$ & Low & $\begin{array}{c}\text { Tong River (R1), Huai River (R2), Huai-Shu River } \\
\text { (R3), New Huaihong River (R4), Old-yellow River (R5), } \\
\text { Xinyi River (R6), Xuhong River (R7) }\end{array}$ \\
\hline Between $10 \%$ and $30 \%$ & Middle & $\begin{array}{c}\text { Yi River (R8), Shu River (R9), Tongyu River (R10), } \\
\text { Sanyang River (R11), Shuiyang River (R12), Zhongyun } \\
\text { River (R13), Liyun River (R14), Taidong River (R15), } \\
\text { Chu River (R16), Bulao River (R17) }\end{array}$ \\
\hline More than $30 \%$ & High & $\begin{array}{c}\text { Qinhuai River (R18), Jiangnan Canal (R19), Wangyu } \\
\text { River (R20), Taipu River (R21) }\end{array}$ \\
\hline
\end{tabular}


Analytic Hierarchy Process (AHP) was proposed in the early 1970s, which can effectively determine the weight value of each index from qualitative analysis to quantitative integration. This method decomposes the target problem into some single factors, and arranges it into a hierarchy structure according to its hierarchical affiliation, and then determines the relative importance of each component by pairwise comparison. It is a typical multi-criteria decision-making method, which combines subjective judgment with objective facts, expresses the views of decision makers quantitatively and reflects the thinking of decomposition, judgment and synthesis in decision making. AHP is used to establish the weight process as Fig. 2.2.

The establishment of hierarchical structure. Construction elements can be divided into: the highest layer (target layer), the middle layer (criterion layer), and the bottom layer (index layer).

Construct pairwise comparison judgment matrix. Digital assignment is used to represent the relative importance of the next layer of elements relative to the previous layer of elements. The $1 \sim 9$ ratio scale method is used to express that $\delta_{i j}$ is the importance scale value of ${ }^{I_{i}}$ and ${ }^{I_{j}}$ relative to the target, then the judgment matrix is $A=\left(\delta_{i j}\right)_{m \times n}$, where $\delta_{i j}>0, \mid \delta_{i i}=1, \delta_{i j}=1 / \delta_{j i}$. 


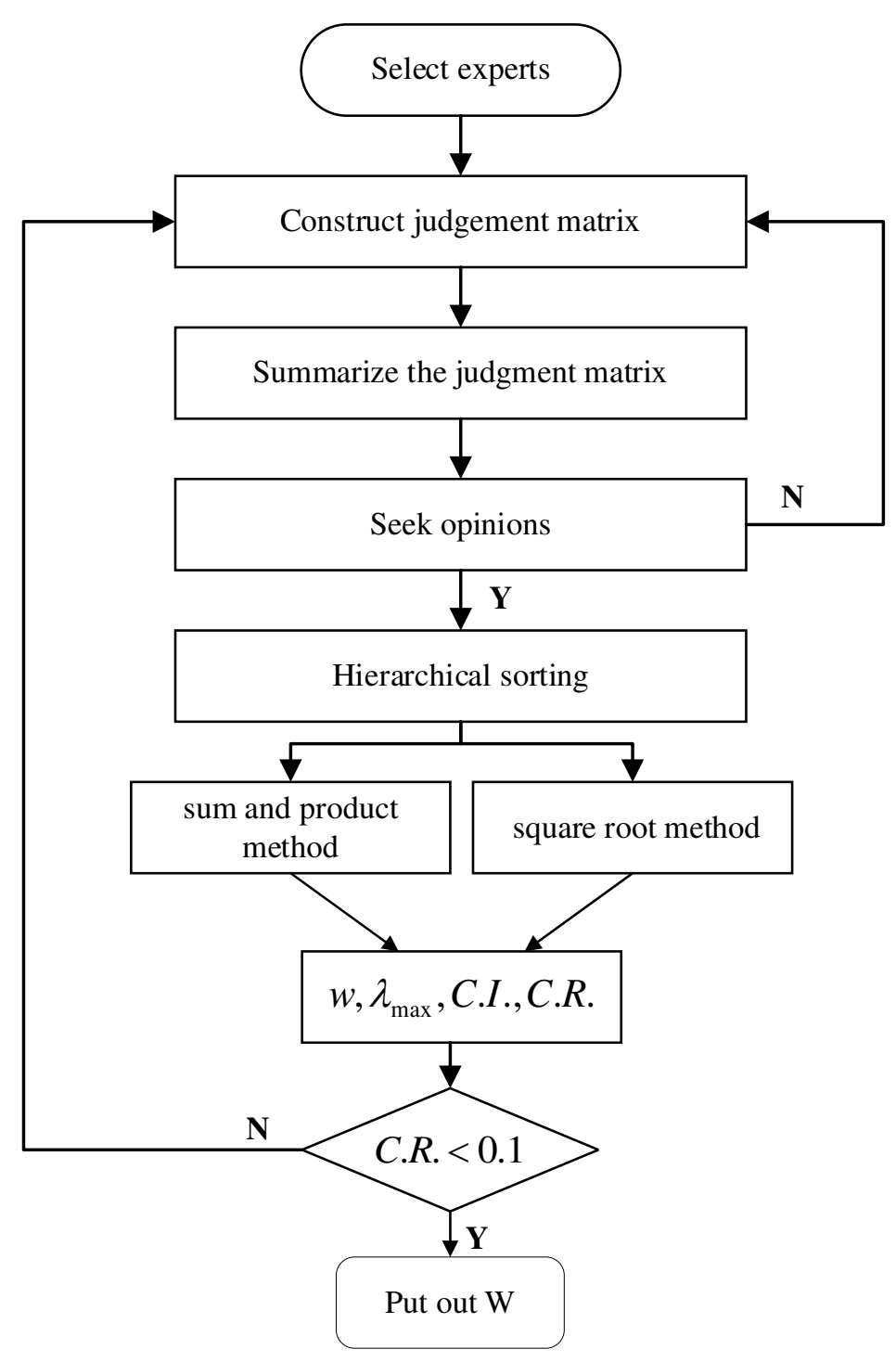

Fig. 2.2 Weighting flowchart of analytic hierarchy process

Single-level sorting. The maximum eigenvalue and maximum eigenvector of the judgment matrix are calculated, and the maximum eigenvector is the weight value of the evaluation index.

Consistency test. The consistency test of the calculated weight value is carried out to ensure the unity and accuracy of each weight value. The changing characteristics of the maximum feature root are analyzed to determine whether the judgment matrix meets the consistency test. The indicators representing the consistency of the judgment matrix are represented by A, and the calculation formula is as follows: 


$$
C . I .=\frac{1}{m-1}\left(\lambda_{\max }-m\right)
$$

Use random consistency ratio C.R. for further accurate judgment: $C R=C I . / R I$. When $C R .<0.1$, the judgment matrix has satisfactory consistency; Otherwise, inconsistent, and the judgment matrix is needed to adjust until its consistency satisfies.

After the single-level sorting and consistency test of the hierarchical total sorting, the value of the importance of the individual factors to the upper-level factors is calculated, and the total sorting is from top to bottom and the layers are recurring.

After the evaluation of river ecological status and the analysis of diverse river ecological status in various indicators under different urbanization levels, the Shapiro-Wilk method was used to test whether the evaluation indicators met the Normal Distribution under low, medium and high urbanization levels. One-way ANOVA was performed on the evaluation indicators that met the normal distribution. Non-parametric test was performed on the evaluation indicators that did not meet the normal distribution. Among them, the results of one-way ANOVA are represented by mean and standard deviation, and the results of non-parametric test are represented by median, upper quartile and lower quartile.

Then, the correlation analysis of the characterization factors of urbanization and river ecological conditions is carried out. The S-W method is used to test whether the ISC and evaluation index values of 21 rivers conform to the normal distribution. When the independent variables and dependent variables meet the normal distribution, the correlation analysis is carried out by Pearson. Otherwise, the Spearman is used for correlation analysis. 


\section{Evaluation of river ecological status}

\subsection{Evaluation indicators and models}

The evaluation of river ecological status in plain river network area is a multi-objective and multilevel problem, for the purpose of clarifying the existing problems and real situation of rivers. Affected by topography, geomorphology, economic development level and other factors, crisscross rivers abound in plain river network area with complex hydrological conditions, poor self-purification capacity of water bodies, frequent floods, serious water pollution problems, and ecological environment vulnerable to the impact of urbanization. Through the analysis of domestic and foreign literature related to the evaluation of ecological rivers after 1985, the influential literature was selected as a reference, and the related concepts of river health, water ecological civilization, ecological rivers and lakes in the literature were systematically analyzed and deconstructed. Accordingly, it can be seen that rivers with good ecological conditions need to meet the needs of social service functions, and have a complete, stable, flexible and sustainable natural ecological system.

The goal of ecological river condition evaluation is summarized as four aspects: aquatic environment, natural ecological system, social service function and water management and protection, and each aspect can be subdivided into multiple indicators. Thus, the evaluation index system of river ecological condition is constructed, and the hierarchical analysis structure model is shown in Fig. 3.1.

According to the calculation formula and evaluation standard of each evaluation index, the scores of each single item of the evaluated river are obtained, which are used as vector elements to form transverse quantities:

$$
U=\left(u_{1}, u_{2}, \mathrm{~L}, u_{i}\right) \quad i=1,2,3 \mathrm{~L}, n
$$


In the formula, $\mathrm{U}$ is the score of the $\mathrm{i}$-th index.

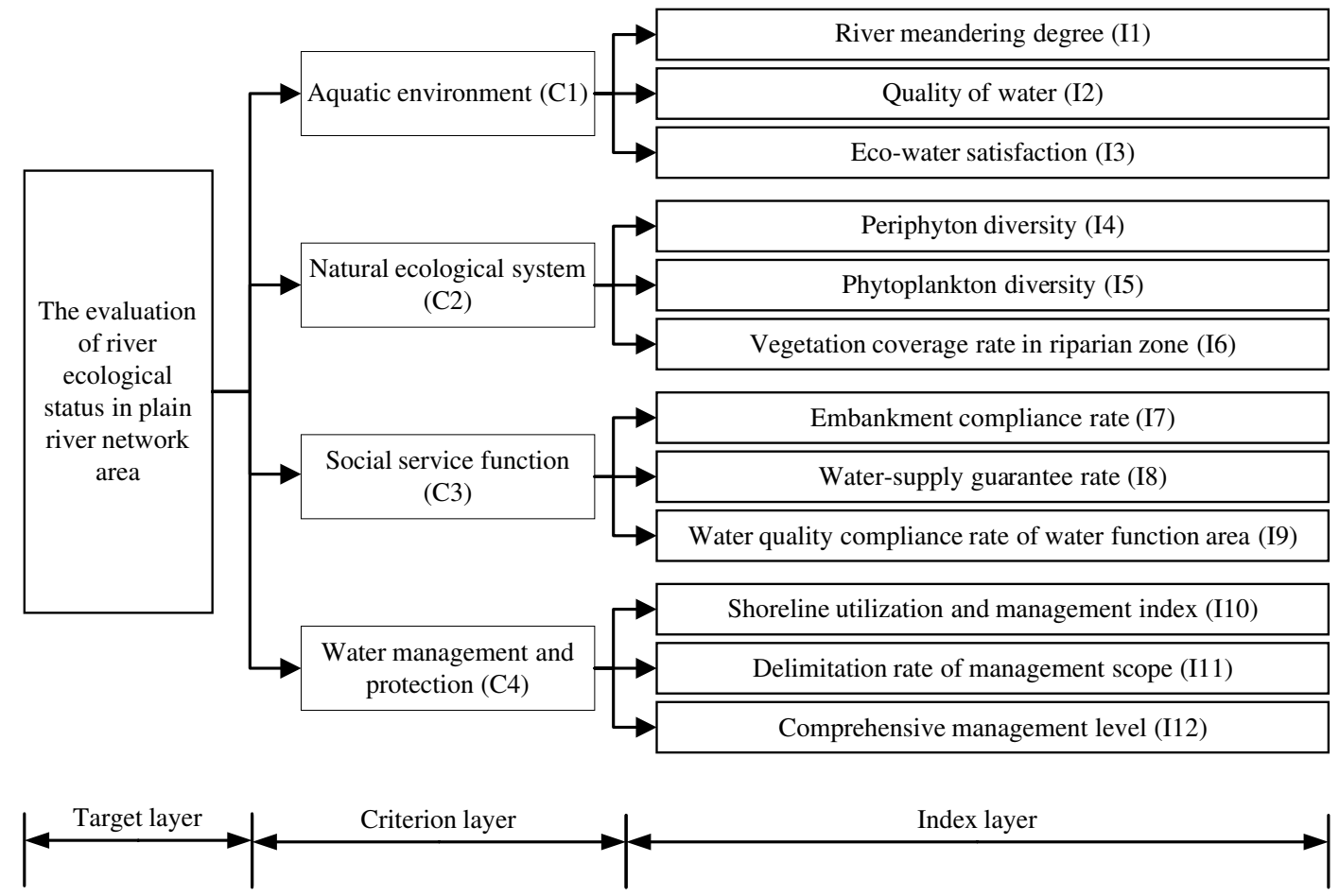

Fig. 3. 1 Hierarchical analysis structure model

The weight value of each evaluation index is calculated, and the weight number of each index is taken as the column vector element to form the column vector:

$$
W=\left(w_{1}, w_{2}, \mathrm{~L}, w_{i}\right)^{T} \quad i=1,2,3 \mathrm{~L}, n
$$

$\mathrm{W}$ is the weight of the $\mathrm{i}-$ th index.

Finally, the vector product of horizontal quantity $U$ and column vector $W$ is used as the comprehensive index of river ecological conditions.

$$
V=U W=\sum_{i=1}^{n} u_{i} w_{i} \quad i=1,2,3 \mathrm{~L}, n
$$

$\mathrm{V}$ is the comprehensive index of river ecological condition.

In this study, the importance ratio of various indicators in the criterion layer is established by the expert evaluation results, and the judgment matrix consistent with the consistency test $(C R<0.1)$ is established by formula 3-3. The weight value of the criterion layer can be obtained by normalizing 
the root method and the sum product method. Similarly, from top to bottom, the weight ratios of each index under the criterion layer are established respectively, so the weight of the evaluation index of river ecological status in plain river network area is shown in Table3.1.

Table 3.1 Evaluation Index Weight of River Ecological Status in Plain River Network Area

\begin{tabular}{|c|c|c|c|}
\hline Number & Criterion layer & Indicator layer & Weight \\
\hline 1 & Aquatic environment & River meandering degree (I1) & 0.06 \\
\hline 2 & $(\mathrm{C} 1)$ & Quality of water (I2) & 0.18 \\
\hline 3 & 0.31 & Ecological water satisfaction (I3) & 0.07 \\
\hline 4 & & Periphyton diversity (I4) & 0.07 \\
\hline 5 & Natural ecosystem (C2) & Phytoplankton diversity (I5) & 0.07 \\
\hline 6 & 0.21 & $\begin{array}{l}\text { Vegetation coverage rate in riparian zone } \\
\text { (I6) }\end{array}$ & 0.07 \\
\hline 7 & 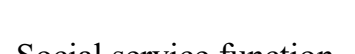 & Embankment compliance rate (I7) & 0.07 \\
\hline 8 & $(\mathrm{C} 3)$ & Water-supply guarantee rate (I8) & 0.06 \\
\hline 9 & 0.21 & $\begin{array}{l}\text { Water quality compliance rate of water } \\
\text { function area (I9) }\end{array}$ & 0.08 \\
\hline 10 & Water management and & $\begin{array}{l}\text { Shoreline utilization and management } \\
\text { index (I10) }\end{array}$ & 0.1 \\
\hline 11 & $\begin{array}{c}\text { protection }(\mathrm{C} 4) \\
0.27\end{array}$ & $\begin{array}{l}\text { Delimitation rate of management scope } \\
\qquad \text { (I11) }\end{array}$ & 0.07 \\
\hline 12 & & Comprehensive management level(I12) & 0.1 \\
\hline
\end{tabular}

\subsection{Index calculation}

The evaluation indexes of river ecological status in plain river network areas can be divided from the four aspects of aquatic environment, natural ecological system, social service function and water management and protection. The specific calculation method is as follows:

\subsubsection{Aquatic environment}

(1) River meandering degree

The river meandering degree characterizes the morphological characteristics of the river, which is mainly used to describe the natural twist of the river shape. The river meandering degree is calculated according to the formula (3-4). According to Pan's study of urban river meandering degree, 
when the actual length of the river is $2 \sim 3$ times the length of its origin and destination straight line, the river meandering degree is good(Pan and $\mathrm{Xu}$ et al., 2015).

$$
C_{1}=\frac{L_{0}}{L_{Z}}
$$

In the above formula: $C_{1}$ is the river meandering; $L_{0}$ is actual length of river; $L_{z}$ is the straight distance between the origin and destination of the river.

(2) Water quality

Water quality is the reflection of river's hydrochemical characteristics in water quality situation. The calculation steps of water quality are as follows:

a. The river length (which is the representative river length of each monitoring section) is used as the weight to calculate the weighted average of the water quality index concentration of each section of the river;

b. For rivers with multiple water quality monitoring results, the arithmetic average concentrations of each water quality index in each section of the river are calculated time by time, and then the weighted average concentrations of each water quality index in each section of the river are calculated according to the length of the river;

c. The single factor evaluation method was used to evaluate the quality of water, and the linear interpolation of the scoring standard corresponding to the concentration value of the worst water quality category index was used. If the indicators in the worst water quality category are not unique, the indicators in the worst water quality category are calculated independently, and the score of the lowest score indicator is taken as the score of the evaluation.

(3) Ecological water satisfaction 
The satisfaction degree of river ecological water refers to the guarantee rate of river ecological flow (and water level) in the control section or characteristic section of the river. The ecological water use satisfaction degree was calculated by the ecological flow calculation method. Two calculation periods were selected from April to September and from October to March of the next year to calculate the ratio of the minimum daily average flow in each period to the average flow over the past 30 years. The minimum value of results for the two periods was taken as the score of river ecological water use satisfaction degree.

\subsubsection{Natural ecological system}

(1) Periphyton diversity

Periphyton diversity mainly characterizes the composition and diversity of Periphyton community in rivers. Unlike benthic animals and plankton, aquatic periphyton features diverse growth habits and dissimilar requirements for the water ecological environment. Therefore, periphytic organisms' condition should be regarded as an important evaluation index in the evaluation of river ecological status. The periphyton diversity was represented by the Shannon-Wiener biodiversity index, and calculated by the following formula. The index score was taken as the linear interpolation of the calculated value corresponding to the evaluation standard.

The Shannon-Wiener biodiversity index formula is as follows(Bashar and Rohani et al., 2020):

$$
H=-\sum_{i}^{S} p_{i} \ln p_{i}
$$

Here, $H$ is the biodiversity index; $S$ are total species; $p_{i}$ is the proportion of the $\mathrm{i}$-th species in the total number of individuals.

(2) Phytoplankton diversity 
River's phytoplankton diversity refers to the diversity characteristics of phytoplankton communities in rivers. The species and quantity of phytoplankton in rivers are closely related to the ecological conditions of rivers. The better the ecological conditions of rivers are, the more species and quantity of phytoplankton in water are. Phytoplankton diversity is calculated by Shannon-Wiener biodiversity index as the following formula and the index score is taken as the linear interpolation of the calculated value corresponding to the evaluation standard.

(3) Riparian vegetation coverage

The vegetation coverage rate of riparian zone means the ratio of the vegetation coverage area of bank and bank slope to the land area of river. The degree of riparian vegetation coverage determines the interception effect of riparian vegetation belt on river pollution. If the riparian vegetation belt is wider, the vegetation coverage rate in the belt is higher, and the adsorption and removal of non-point source pollution such as initial rain pollution is stronger, the river water quality will be more greatly improved. At the same time, the riparian with high vegetation coverage often has better slope stability in extreme weather such as rainstorm and flash flood. The calculation steps of riparian vegetation coverage are as follows:

a. Calculate the vegetation coverage rate of river bank slope and the vegetation coverage rate of river bank;

b. The riparian vegetation coverage was obtained with the weights of riparian slope and riparian vegetation coverage being 0.6 and 0.4 , respectively;

c. Calculate the vegetation coverage rate of the whole river riparian zone with the length of river reach as the weight Using the following calculation, the index score takes the linear interpolation corresponding to the evaluation standard. 
Using the following calculation, the index score takes the linear interpolation corresponding to the evaluation standard.

$$
C_{6}=\sum_{i=1}^{n} \frac{L_{v c i}}{L}\left(0.6 \times \frac{A_{c i 1}}{A_{a i 1}}+0.4 \times \frac{A_{c i 2}}{A_{a i 2}}\right) \times 100 \%
$$

Above, $\mathrm{C} 6$ is the vegetation coverage rate of riparian zone ; $A_{c i l}$ is the vegetation cover area of the bank slope of river section $\mathrm{i} ; A_{a i l}$ is the bank slope area of river section $\mathrm{i} ; A_{c i 2}$ is the vegetation coverage area ashore of the river section $\mathrm{i} ; A_{a i 2}$ is the bank area of river section $\mathrm{i} ; L_{v c i}$ is river length of river section $\mathrm{i}$; $\mathrm{L}$ is the river length evaluated.

\subsubsection{Social service function}

(1) Embankment compliance rate

Embankment compliance rate refers to the ratio of the length of the embankment that meets the flood control standard to the total length of the existing embankment. River flood control and drainage function is the basic and most important function. Moreover, river course stability is the premise to ensure people's lives and property safety. On the basis of the economic and social development status of river protection areas and the importance of protected objects, the following formula is used for calculation. The index score takes the linear interpolation of the calculated value corresponding to the evaluation standard.

$$
C_{7}=\frac{L_{d 0}}{L_{d n}} \times 100 \%
$$

In the formula, $C_{7}$ is the embankment compliance rate; $L_{d 0}$ is the length of the standard embankment; $L_{d n}$ is the total length of the evaluated embankment.

(2) Water-supply guarantee rate

Water-supply guarantee rate stands for the satisfaction degree of all water supply projects. Urban domestic water and industrial water are partly supplied by rivers around the town. Thus, ensuring 
normal domestic water consumption and industrial water consumption is a necessary prerequisite for social stability and economic development. The water-supply guarantee rate of a single water supply project is equal to the ratio of the daily water level of the river to the guaranteed water level within a year. The linear interpolation of the calculated value corresponding to the evaluation standard is used to express the index score.

$$
C_{8}=\frac{\sum_{i=1}^{n}\left(w_{i} \times p_{i}\right)}{\sum_{i=1}^{n} w_{i}}
$$

In the formula, $\mathrm{C}_{8}$ is the water-supply guarantee rate; $w_{i}$ is the average daily water supply for the $\mathrm{i}$-th water supply project; $p_{i}$ is the water-supply guarantee rate for the $\mathrm{i}$-th water supply project; $R_{\mathrm{ul}}$ is the total number of water supply projects for rivers.

(3) Water quality compliance rate of water function area

The water quality compliance rate of water function area is the water quality compliance of regional water function area. The establishment of water function zones is a means of water function division proposed by people to achieve the protection and rational utilization of water resources. Combined with the needs of social and economic development additionally, water resources utilization and river management methods are proposed. The water quality compliance rate of water function areas is expressed by the ratio of the number of water function areas meeting the water quality standards to the total number of the evaluation. The linear interpolation of the evaluation standard is used to calculate the index score. The calculation formula is as follows:

$$
C_{9}=\frac{G_{0}}{G_{n}} \times 100 \%
$$

In the formula, C9 is the water quality compliance rate of the water functional area; $G_{0}$ is the number of water functional areas that reach the standard; $G_{0}$ is the total number of water functional areas.

\subsubsection{Water management and protection}


(1) Shoreline utilization and management index

The shoreline utilization and management index refers to the extent to which river shorelines are well protected in the context of human activities. River shoreline is of great significance to the construction of biological habitat, river storage and discharge, and flow pattern. The better the shoreline is protected, the better the ecological condition of the river is. The shoreline utilization and management index includes two parts: firstly, shoreline utilization rate, namely the ratio of the length of the utilized shoreline to the total length of the river shoreline; secondly, the used shoreline integrity rate, i.e., the ratio of the used shoreline restored to its original state to the total length of the used shoreline.

Referring to relevant specifications, the formula below is used for calculation, and the index score takes the linear interpolation corresponding to the evaluation standard.

$$
C_{10}=\frac{1}{2} \times\left[\left(1-\frac{L_{\mathrm{u}}}{L_{\mathrm{n}}}\right)+\frac{L_{0}}{L_{\mathrm{u}}}\right] \times 100 \%
$$

In the formula, $\mathrm{C} 10$ is the shoreline utilization and management index; $L_{\mathrm{u}}$ is the developed shoreline length; $L_{\mathrm{n}}$ is the total length of the shoreline; $L_{0}$ is the protected length of the used shoreline.

\section{(2) Delimitation rate of management scope}

The delimitation rate of management scope refers to the degree of river management scope delimitation. Expected goal is that the scope of river channel management is clear and the management scope meets the requirements of relevant laws, regulations and norms. The following formula is used for calculation. The index score takes the linear interpolation of the calculated value corresponding to the evaluation standard.

$$
C_{11}=\frac{L_{d}}{L} \times 100 \%
$$


In the formula, $\mathrm{C} 11$ is the management scope delimitation rate; $L_{\mathrm{d}}$ is the length of river which has been delimited management scope; $L$ is the total length of the river evaluated.

(3) Comprehensive management level

The comprehensive management level refers to the degree of management of illegal activities or facilities per unit length of river shoreline, which reflects the scientific degree of river management or the standard treatment of illegal behaviors within the river range. The calculation formula is as follows:

$$
C_{12}=\frac{m}{L_{n h}}
$$

$C_{12}$ is the degree of comprehensive treatment; $\mathrm{m}$ is the number of illegal acts or facilities; $L_{n h}$ is the length of the shoreline.

\subsection{Evaluation criteria}

At present, there is no uniform standard for river ecological status evaluation. The evaluation criteria in various fields correspond to local characteristics. The evaluation criteria of the same river will also change in different periods of its evolution and succession due to the different service functions of the river. The determination of evaluation criteria for river ecological status should follow the following aspects:

(1) Base on the national and local norms and planning;

(2) Refer to the existing research results at home and abroad to determine the ecological factors;

(3) Query the historical data of rivers;

(4) Analogy reference natural environment and social environment similar rivers;

(5) Expert consultation;

(6) Standards to meet public expectations; 
According to the above principles, the comprehensive index of river ecological status evaluation and each evaluation index are divided into four grades: excellent, good, medium and poor. The score is given by linear interpolation in the interval. The summary table of river ecological status evaluation index and evaluation standard is shown in table 3.2.

\subsection{Evaluation results and analysis}

Each index score of typical rivers is substituted into the evaluation model of river ecological status in plain river network area, and the comprehensive index of typical river ecological status is obtained. The scores of typical river ecological status evaluation index and comprehensive index are shown in table 3.3. The comprehensive index of ecological status of 21 main streams and tributaries of rivers ranges from 70.83 to 87.39 , among which the comprehensive index of ecological status of Taipu River (R21) is the lowest, and the comprehensive index of ecological status of Huai-Shu River (R3) is the highest. $71.4 \%$ of the evaluation results of river ecological condition are good, $28.6 \%$ of the evaluation results are medium, no river ecological condition evaluation results are good or bad, no extreme situation. 
Table 3.2 Summary of evaluation index and standard of river ecological condition

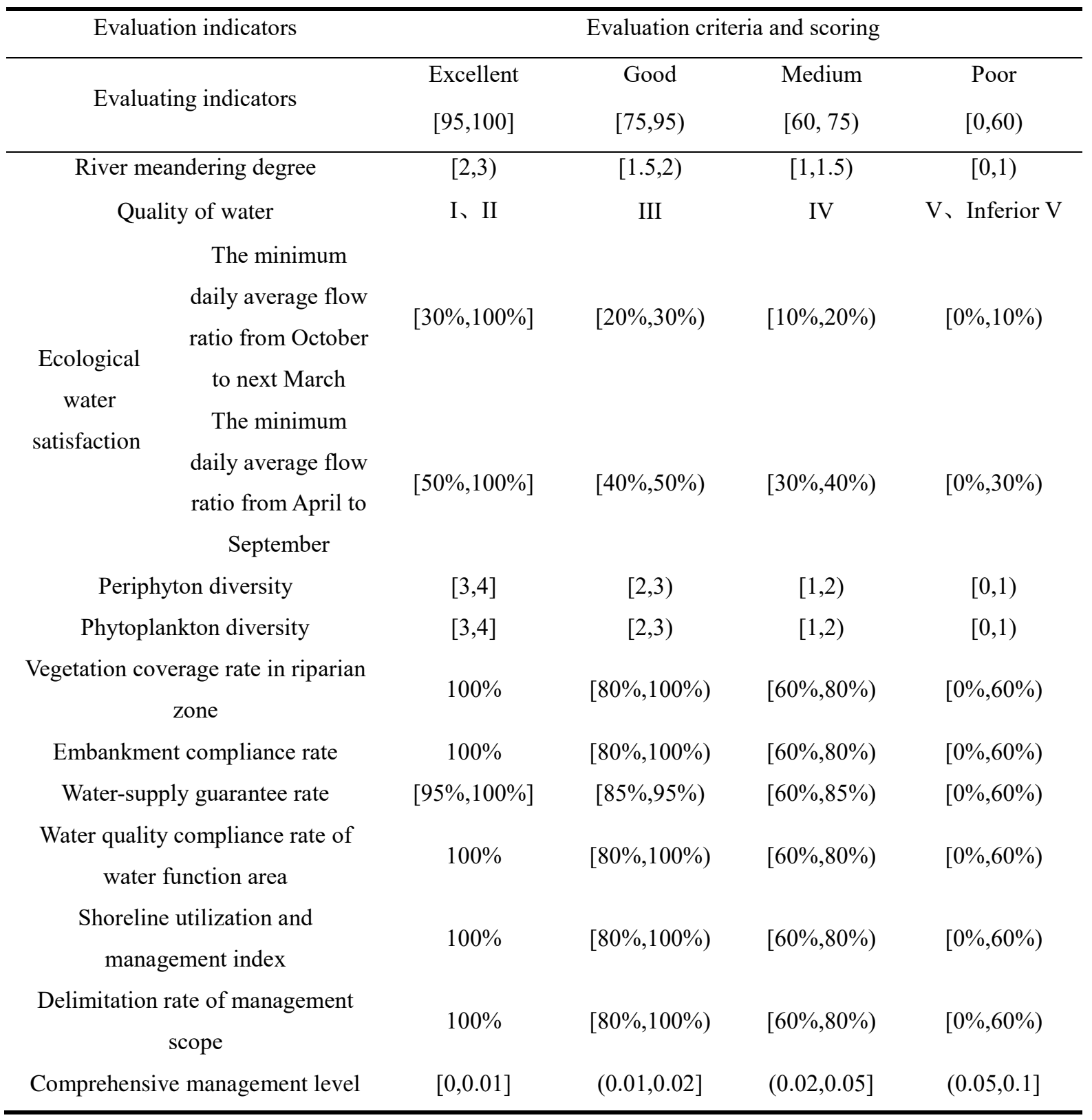


Evaluation of River Ecological Status in Plain River Netw...

Table 3.3 Scores of ecological status evaluation index and comprehensive index of typical rivers

\begin{tabular}{|c|c|c|c|c|c|c|c|c|c|c|c|c|c|c|}
\hline Rivers & $\begin{array}{l}\text { Impervious } \\
\text { coefficient }\end{array}$ & I1 & $\mathrm{I} 2$ & $\mathrm{I} 3$ & $\mathrm{I} 4$ & I5 & I6 & $\mathrm{I} 7$ & I8 & I9 & $\mathrm{I} 10$ & I11 & $\mathrm{I} 12$ & $\begin{array}{c}\text { Comprehensi } \\
\text { ve indexes }\end{array}$ \\
\hline R1 & 0.02 & 60.19 & 72.60 & 100 & 86.85 & 88.65 & 79.28 & 90.00 & 100 & 100 & 85.80 & 100 & 85.50 & 85.94 \\
\hline R2 & 0.05 & 72.84 & 76.95 & 100 & 78.45 & 80.70 & 72.15 & 82.50 & 100 & 100 & 83.48 & 100 & 63.00 & 82.83 \\
\hline R3 & 0.05 & 66.96 & 80.10 & 100 & 74.85 & 87.90 & 80.93 & 90.00 & 100 & 100 & 83.93 & 100 & 92.00 & 87.39 \\
\hline $\mathrm{R} 4$ & 0.06 & 68.38 & 72.75 & 100 & 85.95 & 81.45 & 81.90 & 84.00 & 100 & 100 & 75.00 & 100 & 60.75 & 82.10 \\
\hline $\mathrm{R} 5$ & 0.06 & 60.55 & 72.45 & 100 & 74.55 & 84.30 & 75.45 & 92.00 & 100 & 76.50 & 84.23 & 100 & 96.00 & 83.66 \\
\hline R6 & 0.09 & 61.21 & 71.85 & 100 & 85.65 & 83.85 & 70.05 & 92.00 & 82.35 & 82.51 & 79.65 & 43.50 & 87.00 & 78.07 \\
\hline R7 & 0.09 & 63.75 & 64.65 & 100 & 83.10 & 84.30 & 77.78 & 84.00 & 100 & 76.56 & 71.03 & 100 & 91.50 & 80.88 \\
\hline $\mathrm{R} 8$ & 0.10 & 66.02 & 72.00 & 100 & 89.40 & 88.20 & 66.90 & 75.00 & 100 & 100 & 71.55 & 0 & 34.50 & 70.89 \\
\hline R9 & 0.10 & 71.13 & 59.70 & 100 & 83.10 & 91.30 & 76.05 & 78.00 & 100 & 75.00 & 75.45 & 0 & 66.75 & 71.23 \\
\hline $\mathrm{R} 10$ & 0.10 & 60.13 & 71.10 & 100 & 83.25 & 83.70 & 60.30 & 85.50 & 99 & 45.68 & 57.36 & 100 & 60.75 & 73.70 \\
\hline $\mathrm{R} 11$ & 0.10 & 60.37 & 70.20 & 100 & 83.55 & 87.75 & 78.30 & 72.00 & 100 & 100 & 82.28 & 100 & 94.00 & 84.40 \\
\hline $\mathrm{R} 12$ & 0.11 & 90.88 & 77.55 & 100 & 86.70 & 88.50 & 75.90 & 67.80 & 100 & 100 & 82.95 & 0 & 95.00 & 80.53 \\
\hline $\mathrm{R} 13$ & 0.12 & 66.57 & 75.00 & 100 & 89.55 & 87.60 & 69.53 & 87.00 & 94.60 & 100 & 59.04 & 78.00 & 81.00 & 80.99 \\
\hline R14 & 0.14 & 70.81 & 81.75 & 100 & 72.75 & 83.10 & 73.95 & 87.00 & 100 & 95.00 & 76.50 & 100 & 85.50 & 84.94 \\
\hline $\mathrm{R} 15$ & 0.19 & 64.78 & 77.10 & 100 & 89.55 & 84.45 & 40.00 & 90.00 & 95.60 & 48.00 & 83.03 & 92.50 & 87.00 & 79.03 \\
\hline R16 & 0.20 & 74.61 & 61.05 & 100 & 89.70 & 85.95 & 80.70 & 72.60 & 100 & 66.00 & 82.05 & 100 & 89.25 & 80.90 \\
\hline R17 & 0.19 & 67.97 & 65.55 & 100 & 78.60 & 78.00 & 69.23 & 80.00 & 100 & 66.70 & 78.30 & 72.00 & 88.50 & 77.34 \\
\hline $\mathrm{R} 18$ & 0.30 & 80.57 & 40.80 & 100 & 84.30 & 88.80 & 79.58 & 72.60 & 100 & 10.84 & 82.80 & 100 & 76.50 & 71.74 \\
\hline R19 & 0.31 & 64.14 & 54.00 & 100 & 78.90 & 87.60 & 41.55 & 66.60 & 100 & 76.55 & 85.13 & 64.50 & 91.00 & 74.04 \\
\hline $\mathrm{R} 20$ & 0.38 & 61.86 & 66.45 & 100 & 84.45 & 87.00 & 65.18 & 60.00 & 100 & 34.82 & 85.73 & 76.50 & 92.50 & 75.40 \\
\hline $\mathrm{R} 21$ & 0.42 & 61.15 & 69.45 & 100 & 81.60 & 88.95 & 44.50 & 90.00 & 100 & 0 & 73.05 & 100 & 60.0 & 70.83 \\
\hline
\end{tabular}




\section{Analysis of the impact of urbanization on river ecological status}

\subsection{Differences in river ecological status under different urbanization levels}

In order to analyze the differences of river ecological status under different urbanization levels, the average value of river evaluation scores at different urbanization levels was synthesized, and its significance and whether it meets the normal distribution were verified. The differences of river evaluation indexes in different urbanization levels are shown in table 4.1.

Table 4.1 Differences of river ecological status under different urbanization levels

\begin{tabular}{|c|c|c|c|c|c|}
\hline \multirow{2}{*}{ Evaluated indexes } & \multicolumn{3}{|c|}{ Urbanization levels } & \multirow{2}{*}{ Significance $(\mathrm{P})$} & \multirow{2}{*}{$\begin{array}{c}\text { Whether the normal } \\
\text { distribution is } \\
\text { satisfied or not }\end{array}$} \\
\hline & Low & Medium & High & & \\
\hline River meandering degree(I1) & $64.84 \pm 4.75$ & $69.48 \pm 9.37$ & $64.13 \pm 2.77$ & 0.29 & Yes \\
\hline Quality of water(I2) & $73.05 \pm 4.79$ & $71.72 \pm 7.38$ & $59.25 \pm 11.87$ & 0.02 & Yes \\
\hline $\begin{array}{c}\text { Embankment compliance } \\
\text { rate (I7) }\end{array}$ & $87.79 \pm 4.12$ & $79.43 \pm 8.08$ & $73.84 \pm 11.67$ & 0.02 & Yes \\
\hline $\begin{array}{l}\text { Ecological water satisfaction } \\
\text { (I3) }\end{array}$ & 100.00 & 100.00 & 100.00 & - & Yes \\
\hline $\begin{array}{l}\text { Comprehensive management } \\
\text { level(I12) }\end{array}$ & $82.25 \pm 14.35$ & $77.89 \pm 20.46$ & $69.70 \pm 30.83$ & 0.62 & Yes \\
\hline Comprehensive index & $82.23 \pm 3.53$ & $78.51 \pm 5.32$ & $73.87 \pm 2.65$ & 0.01 & Yes \\
\hline Periphyton diversity (I4) & $\begin{array}{l}83.10(74.85- \\
85.95)\end{array}$ & $\begin{array}{l}86.70(83.18- \\
89.55)\end{array}$ & $\begin{array}{l}81.6(78.75- \\
84.38)\end{array}$ & 0.19 & No \\
\hline Phytoplankton diversity (I5) & $\begin{array}{c}84.30(81.45- \\
87.90)\end{array}$ & $\begin{array}{l}87.60(84.08- \\
88.35)\end{array}$ & $\begin{array}{l}87.60(82.50- \\
88.88)\end{array}$ & 0.40 & No \\
\hline $\begin{array}{l}\text { Shoreline utilization and } \\
\text { management index (I10) }\end{array}$ & $\begin{array}{c}\text { 77.78(72.20- } \\
80.90)\end{array}$ & $\begin{array}{l}74.00(63.60- \\
77.20)\end{array}$ & $\begin{array}{l}63.23(43.03- \\
67.20)\end{array}$ & 0.01 & No \\
\hline $\begin{array}{l}\text { Water-supply guarantee rate } \\
\text { (I8) }\end{array}$ & $\begin{array}{c}100.00(100.00- \\
100.00)\end{array}$ & $\begin{array}{c}100.00(97.30- \\
100.00)\end{array}$ & 100.00 & 0.36 & No \\
\hline
\end{tabular}

The results of difference analysis showed that there were significant differences in river ecological status under different urbanization levels $(\mathrm{p}<0.05)$. The river ecological status in low urbanization level was dramatically better than which in medium and high urbanization levels. The river ecological status in high urbanization level was medium except the Wangyu River (R20), and the river ecological status was significantly affected by urbanization development.

\subsection{Correlation analysis of river ecological status characterization factors, comprehensive} index of river ecological status and ISC

The S-W test method was used to test whether the ISC and the evaluation index values of 21 rivers conformed to the normal distribution. The results showed that the water quality, periphyton diversity, phytoplankton diversity, riparian vegetation coverage, embankment compliance rate, water quality 
compliance rate of water function area, comprehensive management degree and comprehensive index of river ecological status met the normal distribution, and ISC and other evaluation indexes did not meet the normal distribution. Therefore, the Spearman was used to analyze the correlation between ISC and the above eight evaluation indexes. According to the results of correlation analysis, the evaluation indexes with significant correlation with urbanization level or comprehensive index of river ecological status were selected as the characterization factors of river ecological status. Table 4.2 shows the correlation results among characterization factors of river ecological status, ISC and comprehensive index of river ecological status.

Table 4. 2 Correlation analysis of river ecological status characterization factors with river ecological status comprehensive index and ISC

\begin{tabular}{|c|c|c|c|c|c|c|}
\hline & $\begin{array}{l}\text { Quality of } \\
\text { water (I2) }\end{array}$ & $\begin{array}{l}\text { Vegetation } \\
\text { coverage } \\
\text { rate in } \\
\text { riparian zone } \\
\text { (I6) }\end{array}$ & $\begin{array}{l}\text { Embankment } \\
\text { compliance rate } \\
\text { (I7) }\end{array}$ & $\begin{array}{l}\text { Water quality } \\
\text { compliance } \\
\text { rate of water } \\
\text { function area } \\
\text { (I9) }\end{array}$ & $\begin{array}{l}\text { Delimitation } \\
\text { rate of } \\
\text { management } \\
\text { scope (I11) }\end{array}$ & $\begin{array}{l}\text { comprehensive } \\
\text { index }\end{array}$ \\
\hline ISC & $-0.453^{*}$ & $-0.632^{* *}$ & $-0.449^{*}$ & $-0.683^{* *}$ & -0.244 & $-0.542^{*}$ \\
\hline $\begin{array}{l}\text { comprehensive } \\
\text { index }\end{array}$ & $0.636^{* *}$ & $0.632^{* *}$ & 0.241 & $0.651^{* *}$ & $0.489^{*}$ & 1 \\
\hline
\end{tabular}

The table shows that water quality, riparian vegetation coverage, embankment compliance rate, water quality compliance rate of water function area and comprehensive index have significant negative correlation with the urbanization level $(\mathrm{p}<0.05)$; water quality, riparian vegetation coverage, water quality compliance rate of water function area and management scope delineation rate have significant positive correlation with comprehensive index $(\mathrm{p}<0.05)$. It shows that the urbanization level has a negative impact on the embankment compliance rate, the compliance rate of water quality in water function areas, water quality, the vegetation coverage rate of riparian zone and the comprehensive index, thus ultimately affecting the ecological status of rivers.

The composite index is linearly fitted with ISC (impervious surface), and the fitting results are shown in Fig. 4.3. 


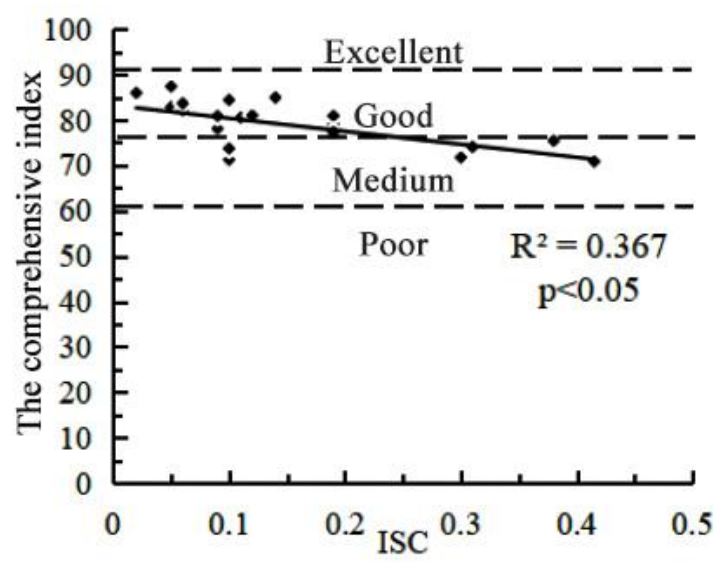

Fig. 4.3 Linear fitting results of the comprehensive index of river ecological status and ISC

As shown in Fig.4.3, the comprehensive index of river ecological status in plain river network area fits a good linear relationship with the ISC. The data points of the comprehensive index of each river distribute almost evenly and symmetrically on both sides of the fitting line, indicating that ISC has a significant and direct negative impact on river ecological status, and the improvement of urbanization level will dramatically reduce the river ecological status. It can be seen from the analysis that the fitting line and the line $y=75$ intersect at the point $(0.28,75)$, that is, when ISC is greater than $28 \%$, the comprehensive index of river ecological conditions changes from good to medium. Therefore, this threshold can be used as the critical value of urbanization development to guide the construction of ecological rivers, namely the reference value of the planning red line; at the same time, when the ISC is small $(<10 \%)$, the comprehensive index of river ecological status is still not excellent, indicating that the river ecological status is affected by other factors in addition to the level of urbanization, which suggests that it entails not only controlling the urbanization, but also taking into account other aspects of the impact on the river ecological status.

To sum up, the management and restoration of ecological rivers should focus on the control of urbanization level and the impervious area from the perspective of overall basin management. Specifically, measures should be taken to improve the poor ecological conditions of rivers in middle and high urbanization areas from the aspects of rational planning of urban land use, restoration of aquatic environment, protection of social service functions, and strengthening water management and 
protection. Meanwhile, $28 \%$ of ISC can be used as the red line reference value of river ecological conditions in urbanization planning from good to medium, so as to coordinate urban development and ecological river construction, and construct a scientific development system of river environment and social economy.

\section{Discussion}

The Analytic Hierarchy Process can be more scientific and reasonable to determine the weight of each evaluation index of river ecological status evaluation, but the method to establish the weight is mainly affected by the subjectivity of decision makers. Thus, owing to the uncertainty of index weight to some extent, it is necessary to adjust the index weight for sensitivity analysis to test the stability of the model(Zhu and Jia et al., 2019). In order to test the influence of the fluctuation of the weight on the evaluation results, the aquatic environment $C_{1}$ and water quality $I_{2}$, the indexes with the highest importance in the criterion layer and the index layer, were selected as representatives to compare the difference between the comprehensive index evaluation results of river ecological conditions and the original weight scheme under the condition of $20 \%$ fluctuation of the weight.

When the weights of criterion layer and index layer were adjusted, the weights of other indexes were also changed accordingly. After recalculating the comprehensive index of river ecological conditions, and the comprehensive index when the weight fluctuates by $20 \%$ are shown in Table 5.1 . In comparison, only when the weight of criterion layer is floating, the comprehensive index changes greatly; when the weight of index layer is floating, the comprehensive index changes little. Overall, when the relative importance order of each evaluation index is fairly clear, the slight adjustment of the weight of each level has little effect on the final evaluation results, and the comprehensive evaluation level has not changed. It is concluded that the evaluation results are not sensitive to the small fluctuation of the functional weight. Therefore, the evaluation model of river ecological status in plain river network area obtained in this study has high stability and reliability. 
Table 5.1 Comprehensive Index of Weight Floating $20 \%$

\begin{tabular}{|c|c|c|c|c|c|}
\hline \multirow{3}{*}{ Rivers } & \multirow{3}{*}{$\begin{array}{c}\text { Original } \\
\text { Comprehensive } \\
\text { index }\end{array}$} & \multirow{2}{*}{\multicolumn{2}{|c|}{$\begin{array}{l}\text { Weight floating of } \\
\text { criterion layer }\end{array}$}} & \multicolumn{2}{|c|}{ Weight floating of } \\
\hline & & & & inde & \\
\hline & & $1.2 C_{1}$ & $0.8 C_{1}$ & $1.2 I_{2}$ & $0.8 I_{2}$ \\
\hline $\mathrm{R} 1$ & 85.94 & 85.45 & 86.62 & 85.48 & 85.69 \\
\hline $\mathrm{R} 2$ & 82.84 & 82.76 & 82.93 & 82.63 & 82.26 \\
\hline R3 & 87.39 & 87.14 & 87.78 & 87.13 & 86.83 \\
\hline $\mathrm{R} 4$ & 82.10 & 81.88 & 82.38 & 81.78 & 81.70 \\
\hline R5 & 83.66 & 83.35 & 84.24 & 83.27 & 83.32 \\
\hline R6 & 78.07 & 78.01 & 78.23 & 77.85 & 77.55 \\
\hline R7 & 80.88 & 80.45 & 81.50 & 80.32 & 80.82 \\
\hline R8 & 70.89 & 71.22 & 70.42 & 70.93 & 70.10 \\
\hline R9 & 71.23 & 71.15 & 71.19 & 70.82 & 71.04 \\
\hline R10 & 73.70 & 73.99 & 73.76 & 73.61 & 73.06 \\
\hline R11 & 84.40 & 83.88 & 85.03 & 83.90 & 84.20 \\
\hline R12 & 80.53 & 80.66 & 80.08 & 80.43 & 79.84 \\
\hline R13 & 80.99 & 80.91 & 81.15 & 80.78 & 80.44 \\
\hline R14 & 84.94 & 84.93 & 85.07 & 84.83 & 84.21 \\
\hline R15 & 79.10 & 79.31 & 79.21 & 79.03 & 78.37 \\
\hline R16 & 80.90 & 80.40 & 81.47 & 80.21 & 81.01 \\
\hline R17 & 77.34 & 77.17 & 77.62 & 76.93 & 77.10 \\
\hline R18 & 71.75 & 71.15 & 72.45 & 70.67 & 72.48 \\
\hline R19 & 74.05 & 73.55 & 74.52 & 73.35 & 74.23 \\
\hline R20 & 75.40 & 75.38 & 75.67 & 75.09 & 75.04 \\
\hline R21 & 70.83 & 71.32 & 70.85 & 70.78 & 70.16 \\
\hline
\end{tabular}

\section{Conclusions}

Based on the background of urbanization, we constructed the evaluation index system and evaluation model of river ecological status in this study, which includes 4 indexes and 12 pieces of criteria suitable for plain river network area, and draws the following conclusions through the 
evaluation of ecological river status and the analysis of the impact of urbanization on river ecological status:

(1) Among the selected 21 typical rivers in Jiangsu Province, $71.4 \%$ of the river ecological status is good, $28.6 \%$ of the river ecological status is medium, and no river is excellent or poor.

(2) The analysis of the differences of river ecological status under different urbanization levels showed that the level of river ecological status generally decreased with the improvement of urbanization level. The differences of river ecological status were mainly reflected in the degree of water quality, the coverage rate of vegetation in riparian zone, the rate of embankment reaching the standard and water quality compliance rate of water function area. The differences of ecological status were mainly reflected in the degree of water quality, riparian vegetation coverage, embankment compliance rate, water quality compliance rate of water function area, etc.

The results of correlation analysis between urbanization and ecological status evaluation showed that there was a significant negative correlation between urbanization level and water quality, riparian vegetation coverage, embankment compliance rate, and water quality compliance rate in water function areas. The threshold of ISC in river ecological status evaluation from good to medium was $28 \%$, which can be used as a reference value for urbanization planning to guide the construction of ecological rivers.

In the management and restoration of ecological rivers, the control of the urbanization level of the basin should be taken as the focal point of governance, and the impervious area of the city should be controlled. Efforts should be made to improve the poor ecological conditions of rivers in medium and high urbanization areas from the aspects of rational planning of urban land, restoration of aquatic environment, protection of social service functions, and strengthening of water management and protection. 
Author Contributions Li Ren contributed to conceptualization, methodology and supervision. Shuping Song contributed to data collection and writing-original draft preparation. Yue Zhou contributed to visualization, investigation.

Funding This work was supported by the National Key R\&D Program of China [grant number 2018YFC1508200].

Data Availability The data are not publicly available due to restrictions such their containing information that.

\section{Declarations}

Ethical Approval All procedures performed in studies involving human participants were in accordance with the ethical standards of the institutional and/or national research committee and with the 1964. Helsinki declaration and its later amendments or comparable ethical standards.

Consent to Participate Informed consent was obtained from all individual participants included in the study.

Consent to Publish All the authors give the Publisher the permission of the authors to publish the research work.

Conflicts of Interest The authors have no conflicts of interest to declare.

\section{References}

Anoop, K. S. and S. P. O. Chandra, et al. (2020). "Influence of Spatial Urbanization on Hydrological Components of the Upper Ganga River Basin, India." Journal of Hazardous, Toxic, and Radioactive Waste 24 (4). 
B, F. R. A. and P. B. A. B, et al. (2016). "Exploring the hydrological impact of increasing urbanisation on a tropical river catchment of the metropolitan Jakarta, Indonesia." Sustainable Cities and Society 20: 210-221.

Bashar, A. and M. F. Rohani, et al. (2020). "Ichthyo-diversity assessment of the Old Brahmaputra river, Bangladesh: present stance and way forward." Heliyon 6 (11): e05447-e05447.

Elizabeth, B. and S. Stacey, et al. (2002). "Impervious Surfaces and Water Quality: A Review of Current Literature and Its Implications for Watershed Planning." Journal of Planning Literature $16(4)$.

Kim, H. W. and M. H. Li, et al. (2016). "Examining the Impact of Suburbanization on Surface Runoff using the SWAT." International Journal of Environmental Research 10 (3): 379-390.

Krisanti, M. and Y. Wardiatno, et al. (2017). "Assessing the ecological status of the Cisadane River's headwaters using benthic macroinvertebrates." IOP conference series. Earth and environmental science 54: 12023.

Meador, M. R. and T. R. Whittier, et al. (2008). "Evaluation of an index of biotic integrity approach used to assess biological condition in western US streams and rivers at varying spatial scales." TRANSACTIONS OF THE AMERICAN FISHERIES SOCIETY 137 (1): 13-22.

Meyer, P. J. L. (2001). "Streams in the Urban Landscape." Annual Review of Ecology \& Systematics 32: 333-333.

Pan, G. and Y. Xu, et al. (2015). "Analysis of river health variation under the background of urbanization based on entropy weight and matter-element model: A case study in Huzhou City in the Yangtze River Delta, China." Environmental Research 139 (may): 31-35.

Paul, M. J. and J. L. Meyer (2008). Streams in the Urban Landscape. Urban Ecology: An International Perspective on the Interaction Between Humans and Nature. J. M. Marzluff, E. Shulenberger and W. Endlicheret al. Boston, MA, Springer US: 207-231. 
Pinheiro, C. and U. Oliveira, et al. (2020). "Assessing the ecological status of a Mediterranean river: benthic invertebrates and diatoms as complementary bioindicators." LIMNETICA 39 (1): 299315.

Tatenda, D. and N. C. Ross, et al. (2020). "Benthic diatom-based indices and isotopic biomonitoring of nitrogen pollution in a warm temperate Austral river system." Science of the Total Environment 748.

Vörösmarty, C. J. and P. B. McIntyre, et al. (2010). "Erratum: Global threats to human water security and river biodiversity." Nature 468 (7321): 334-334.

Youpeng, X. and X. Jintao, et al. (2010). "Impacts of urbanization on hydrology in the Yangtze River Delta, China." Water science and technology : a journal of the International Association on Water Pollution Research 62 (6).

Zezhong, Z. and Q. Qingqing (2016). "River System Health Comprehensive Evaluation of Qilihe in Zhengzhou." International Journal of Earth Sciences and Engineering 9 (2).

Zhu, D. and H. Jia, et al. (2019). "Comprehensive Health Evaluation of the Middle and Lower Hanjiang River." Journal of Hydroecology 40 (1674-3075(2019)40:1<1:HJZXYH>2.0.TX;231): $1-8$. 